\title{
Give patients access to their medical records
}

\author{
Fiona Godlee editor in chief
}

The BMJ

Last week nearly 3000 healthcare providers and users attended the International Forum for Quality and Safety in London. Hosted by The BMJ and the Institute for Healthcare Improvement, it's always an inspiring event. You can watch recorded sessions (http://internationalforum.bmj.com/london), and I encourage you to sign up for the Asia Forum in Kuala Lumpur in August and for next year's International Forum in Amsterdam (http://bit.ly/2pTIi6P).

This time delegates got even more than they bargained for, thanks to the patients who joined the steering and programme committees and led plenary and parallel sessions. They contributed not only as patient representatives but as leaders of system redesign and as innovators in improving their own care. Among others we heard from Margaret Murphy, who, after her son Kevin died as a result of medical error, took up the cause of patient safety and now chairs WHO's Patients for Patient Safety. We also heard Tim Omer and Sara Riggare explain, from their experience of living with, respectively, type 1 diabetes and early onset Parkinson's disease, why they are not waiting for health professionals or the industry to deliver the improvements they need (\#wearenotwaiting). Their closing challenge echoed through the rest of the conference: how will you care for the empowered patient?

Patient empowerment is at the heart of a radical redesign of care and organisational restructure at Karolinska University Hospital in Sweden (doi:10.1136/bmj.j2088). Fresh from his success in turning round Radboud University Medical Centre in the Netherlands (doi:10.1136/bmj.g5765), Karolinska chief executive Melvin Samsom is determined to transform the experience of patients and has involved them at every stage. New structures have been created around 400 patient groups, whose journeys through the health system have been mapped, he explains. In place of separate specialty clinics and departments, care pathways will be centred on patients, not clinicians. Samsom sounds buoyant despite the almost universal unhappiness of Karolinska's doctors. Success will be judged, he says, on how well these new pathways deliver outcomes that matter to patients.

Whether or not the new model delivers on its promise, Sweden is steaming ahead with patient empowerment. This year it will achieve universal online access of patients to their full medical records. As Stephen Armstrong explains (doi:10.1136/bmj. j2069), this has taken time, a need to overcome resistance among clinicians, and a change in the law. Other countries, including the UK, are overcoming similar challenges. Patients across the US, Canada, Australia, the Netherlands, and elsewhere in Europe are gaining access to their records, and the UK government has promised universal access by 2020 . If Sweden can do it, so can we all. 